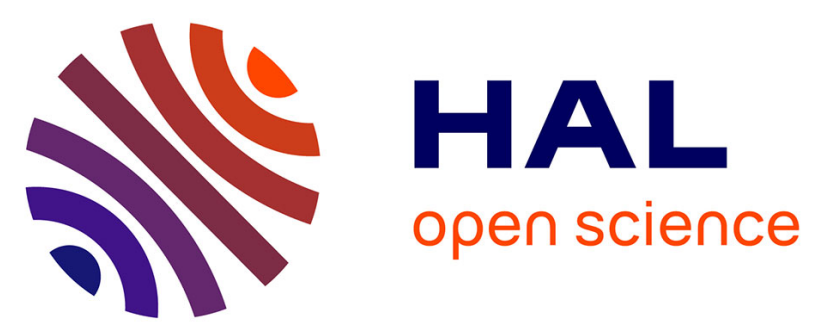

\title{
DIRECT NUMERICAL SIMULATION OF COMPRESSIBLE FLOWS AROUND SPHERICAL BODIES USING THE IMMERSED BOUNDARY METHOD
}

Hamza Riahi, Eddy Constant, Julien Favier, Philippe Meliga, Eric Serre, Marcello Meldi, Eric Goncalves da Silva

\section{To cite this version:}

Hamza Riahi, Eddy Constant, Julien Favier, Philippe Meliga, Eric Serre, et al.. DIRECT NUMERICAL SIMULATION OF COMPRESSIBLE FLOWS AROUND SPHERICAL BODIES USING THE IMMERSED BOUNDARY METHOD. Direct and Large-Eddy Simulation, May 2017, Pisa, Italy. hal-01569248

\author{
HAL Id: hal-01569248 \\ https://hal.science/hal-01569248
}

Submitted on 23 Apr 2018

HAL is a multi-disciplinary open access archive for the deposit and dissemination of scientific research documents, whether they are published or not. The documents may come from teaching and research institutions in France or abroad, or from public or private research centers.
L'archive ouverte pluridisciplinaire HAL, est destinée au dépôt et à la diffusion de documents scientifiques de niveau recherche, publiés ou non, émanant des établissements d'enseignement et de recherche français ou étrangers, des laboratoires publics ou privés. 


\title{
DIRECT NUMERICAL SIMULATION OF COMPRESSIBLE FLOWS AROUND SPHERICAL BODIES USING THE IMMERSED BOUNDARY METHOD
}

\author{
H. Riahi, E. Constant, J. Favier, P. Meliga, E. Serre, M. Meldi, and E. Goncalves
}

\section{Introduction}

The three-dimensional flow around a sphere is one of the most classical subjects of investigation for fundamental analysis of external aerodynamics. In fact this flow configuration, which is described by a very simple geometrical shape, exhibits the potential for complex multi-physics analysis. Some aspects that can be investigated include turbulence, acoustics and heat transfer, and this test case is particularly favorable for the analysis of coupled problems. In addition, the emergence of a number of different regimes is observed for moderate Reynolds number, which are extremely sensitive to the Mach number Ma investigated. Furthermore, multiple physical systems can be modeled by multi-spherical bodies in motion involving complex interactions. Owing to this large number of aspects which are relevant for industrial applications, this case represents an important benchmark for validation of new numerical /modeling strategies.

In the present work, this test case is analyzed via the Immersed Boundary Method (IBM). The surface of the sphere is not directly embedded in the physical domain, but it is represented by a set of discrete Lagrangian points which are associated with volume forces included in the Navier-Stokes equation. This procedure allows for flow representation through Cartesian grids, instead of the classical solution of a spherical frame of reference. This analysis aims to produce ground research for future fluid structure interactions analysis, including moving spherical objects in the physical domain. In this scenario, the use of a spherical frame of reference is clearly problematic.

H. Riahi · M. Meldi · E. Goncalves

Institut PPRIME, Department of Fluid Flow, Heat Transfer and Combustion, ENSMA - CNRS

- Université de Poitiers, UPR 3346, Poitiers, France., e-mail: \{hamza.riahi, marcello. meldi, eric.goncalves\} @ensma. fr

E. Constant $\cdot$ J. Favier $\cdot$ P. Meliga $\cdot$ E. Serre

Aix-Marseille Université, CNRS,Ecole Centrale Marseille, Laboratoire M2P2 UMR 7340, 13451, Marseille, France. 
The flow configurations here investigated encompass a large range of $M a$ numbers, including subsonic, transonic and supersonic flows, for low to moderate Reynolds numbers $R e$. This very large parametric two dimensional space $[M a, R e] \in$ $[0.3-2,50-600]$ allows for a robust validation of the proposed IBM methodology, which must achieve a successful representation for numerous physical configurations exhibiting different features.

\section{Numerical ingredients and IBM development}

The starting point of the present work are the compressible Navier-Stokes equations:

$$
\begin{aligned}
& \frac{\partial \rho}{\partial t}+\operatorname{div}(\rho \mathbf{U})=0 \\
& \frac{\partial \rho \mathbf{U}}{\partial t}+\operatorname{div}(\rho \mathbf{U} \otimes \mathbf{U})=-\operatorname{grad} p+\operatorname{div} \overline{\bar{\tau}}+\mathbf{F} \\
& \frac{\partial \rho E}{\partial t}+\operatorname{div}(\rho E \mathbf{U})=-\operatorname{div}(p \mathbf{U})+\operatorname{div}(\overline{\bar{\tau}} \mathbf{U})+\operatorname{div}(\lambda(T) \operatorname{grad} T)+\mathbf{F} \mathbf{U}
\end{aligned}
$$

where $\rho$ is the density, $p$ the pressure, $T$ the temperature, $\lambda$ the thermal conductivity, $\mathbf{U}$ the velocity, $\overline{\bar{\tau}}$ the tensor of the viscous constraints, $E$ the total energy and $\mathbf{F}$ a prescribed volume force. The IBM exploits this last term to account for the presence of the immersed body, which is not represented via a boundary condition. Among the favorable characteristics of this method we have that mesh elements are not stretched / distorted close to the body surface. In addiction, expensive updates of the mesh are naturally excluded in the analysis of moving bodies.

The present method roots in previous works proposed by Uhlmann [9] and Pinelli et al. [8] which combine strengths of classical continuous forcing methods [7] and discrete forcing methods [5].

The novelty of the approach is represented by:

1. the extension to compressible flow configurations

2 . the addition of a component which penalizes deviation from the expected behavior of the pressure gradient. In numerical simulation, the pressure field must comply with a Neumann condition in the wall normal direction.

The forcing is calculated on Lagrangian points representing the discretized shape of the body via interpolation of the physical fields available on the Eulerian Cartesian Grid. This step is followed by a consistent spreading of this value back to the Eulerian mesh elements. The resulting forcing term $F$ in Eulerian coordinates, which will be referred to as $F_{I B}$, is expressed as:

$$
\mathbf{F}_{I B}=\frac{1}{\Delta t} \rho_{\text {interpol }}\left(\mathbf{U}_{\text {target }}-\mathbf{U}_{\text {interpol }}\right)-\left(\operatorname{grad} p_{\text {target }}-\operatorname{grad} p_{\text {interpol }}\right)
$$


here the subscript interpol represents the quantities that have been interpolated on the Lagrangian points, while the subscript target represents the expected behavior of the flow close to the wall. $\Delta t$ is the time step of the numerical simulation.

\section{Numerical implementation \& validation}

The implementation of the IBM model has been performed in the framework of a specific open source library for numerical simulation, namely OpenFOAM. This code has been identified as the best tester because of the simplicity in implementation as well as the availability of numerous routines already integrated [1]. Owing to the large spectrum of $M a$ numbers investigated, the IBM has been implemented in two different solvers:

- segregated pressure-based solver with pimple loop for compressible flow with low Mach number $(M a \leq 0.3)$ [3].

- segregated density-based solver with Kurganov and Tadmor divergence scheme for compressible flow with high Mach number $(M a>0.3)[10]$.

Two 2D test cases have been identified to validate the performance of the compressible IBM solver, namely the flow around a circular cylinder and the flow around a three cylinders configuration. For both test cases, numerical results indicate that the present version of the IBM successfully captures the physical features over the whole parametric space investigated. In addition, the pressure correction term in equation 4 proves to be essential in obtaining an accurate near wall estimation of the flow. Results are shown for reference in figure 1a for the unsteady subsonic flow around circular cylinder, where the Karman street is correctly represented, and in figure $1 \mathrm{~b}$ for the supersonic flow around a three cylinder configuration. For this last case, it is observed that the presence of the lateral cylinders decreases the drag coefficient of the central cylinder.

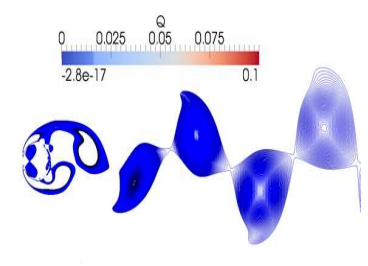

Fig. 1a Q-Criterion for a 2D subsonic flow around a circular cylinder, $\mathrm{Ma}=0.3$

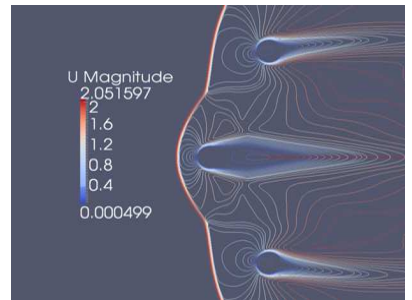

Fig. 1b Mach isocontours for a 2D supersonic flow around a circular cylinders , $\mathrm{Ma}=2$ 


\section{DNS of compressible flows around a sphere}

The three-dimensional flow around a sphere has been investigated for different configurations including subsonic, transonic and supersonic flow cases. Present results are compared with classical DNS by Nagata [6] for embedded surfaces using a spherical mesh. The near wall Cartesian mesh resolution has been fixed accordingly with Johnson and Patel formula for direct numerical simulation [2], resulting in cubic elements of resolution $0.0078 D$, where $D$ is the sphere diameter. This level of refinement is imposed in a region of size $x \times y \times z=[-1,1] \times[-1,1] \times[-1,1]$ in $D$ units. The origin is fixed in the center of the sphere. A progressive coarsening ratio is imposed outside this region, resulting in a total of $2 \times 10^{7}$ mesh elements. As discussed in the introduction, this test case exhibits numerous physical configurations which are sensitive to the value of $M a$ and $R e$ initially imposed. Results for nine configurations are here discussed, as summarized in table 1. Depending on the choice of the parameters $M a, R e$ a steady axisymmetric configuration or an unsteady flow configuration is observed.

Table 1 Flow regimes

\begin{tabular}{cccc}
\hline & SUBSONIC LOW MACH & TRANSONIC FLOW & SUPERSONIC FLOW \\
& $\mathrm{Ma}=0.3$ & $\mathrm{Ma}=0.95$ & $\mathrm{Ma}=2$ \\
\hline $\mathrm{Re}=50$ & STEADY AXISYMMETRIC STEADY AXISYMMETRIC & STEADY AXISYMMETRIC \\
$\mathrm{Re}=300$ & UNSTEADY & STEADY AXISYMMETRIC STEADY AXISYMMETRIC \\
$\mathrm{Re}=600$ & UNSTEADY & UNSTEADY & STEADY AXISYMMETRIC \\
\hline
\end{tabular}

A very good agreement with results in the literature $[4,6]$ is observed for all the configurations investigated. In particular, results for the bulk flow quantities (friction coefficient $C_{D}$, recirculation bubble $X s$, Strouhal number $S t$ and shock distance from stagnation point $D$ shock) are presented in table 2 . In the following, a brief discussion is proposed clustering the results with respect to the Mach number.

Table 2 Results of a 3D compressible flow around sphere

\begin{tabular}{|c|c|c|c|c|c|c|c|c|c|c|}
\hline & & \multicolumn{3}{|c|}{$\mathrm{Ma}=0.3$} & \multicolumn{3}{|c|}{$\mathrm{Ma}=0.95$} & \multicolumn{3}{|c|}{$\mathrm{Ma}=2$} \\
\hline & & $C_{D}$ & $\overline{X s}$ & $\mathrm{St}$ & $C_{D}$ & $\mathrm{Xs}$ & $\mathrm{St}$ & $C_{D}$ & $\mathrm{Xs}$ & Dshock \\
\hline \multirow[t]{2}{*}{$\mathrm{Re}=50$} & IBM Results & 1.6 & 0.96 & - & 2.116 & 1.15 & & 2.03 & 0.5 & 0.73 \\
\hline & Nagata et al.[6] & 1.57 & 0.95 & - & - & - & & 2.25 & 0.5 & 0.75 \\
\hline \multirow[t]{2}{*}{$\mathrm{Re}=300$} & IBM Results & 0.703 & - & 0.123 & 1.03 & 3.8 & & 1.39 & 1 & 0.7 \\
\hline & Nagata et al.[6] & 0.68 & - & 0.128 & 1 & 4.1 & & 1.41 & 1 & 0.7 \\
\hline \multirow[t]{2}{*}{$\mathrm{Re}=600$} & IBM Results & 0.58 & - & 0.143 & 0.91 & - & 0.138 & 1.27 & 1.7 & 0.68 \\
\hline & Krumins.[4] & 0.54 & - & - & 0.9 & - & - & 1.17 & - & - \\
\hline
\end{tabular}

The subsonic flow configuration for $M a=0.3$ clearly exhibits an stationary behavior for $R e=50$, while unsteady flows are obtained for $R e=300$ and $R e=600$ (see figures $2 \mathrm{a}$ and $2 \mathrm{~b}$ ). For the unstationary cases, the IBM method allows for a precise estimation of the bulk statistical quantities. 


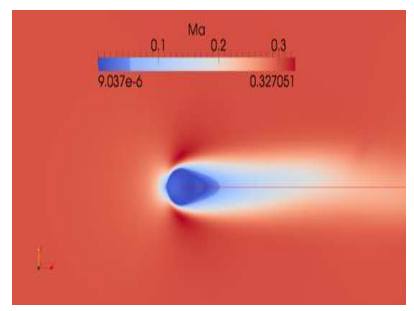

Fig. 2a Mach isocontours for a 3D steady flow around a sphere, $\mathrm{Ma}=0.3 \mathrm{Re}=50$

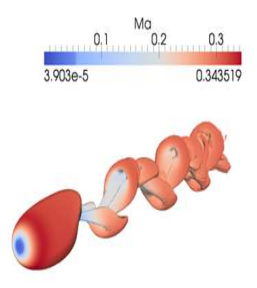

Fig. 2b Q-Criterion for a 3D unsteady flow around a sphere , $\mathrm{Ma}=0.3 \mathrm{Re}=300$

The results obtained for the transonic case $(M a=0.95)$ are shown in figures 3a, $3 \mathrm{~b}, 3 \mathrm{c}$ and $3 \mathrm{~d}$. For this case, steady configurations are observed for $R e=50$ and $R e=$ 300 , while an unsteady flow is obtained for $R e=600$. The most interesting aspect for this class of simulations is that an accurate representation of the supersonic zone at the wall is observed, which is usually a challenging point for IBM methods.

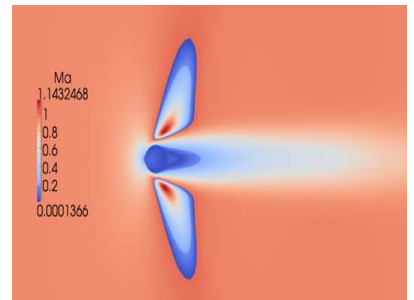

Fig. 3a Mach isocontours for a 3D steady flow around a sphere, $\mathrm{Ma}=0.95 \mathrm{Re}=50$

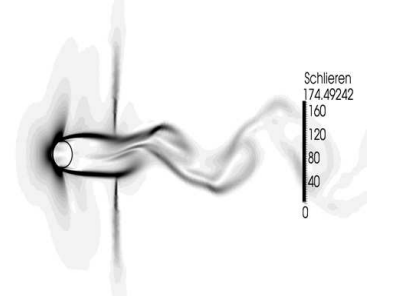

Fig. 3c Schlieren Criterion of a 3D steady flow around a sphere, $\mathrm{Ma}=0.95 \mathrm{Re}=600$

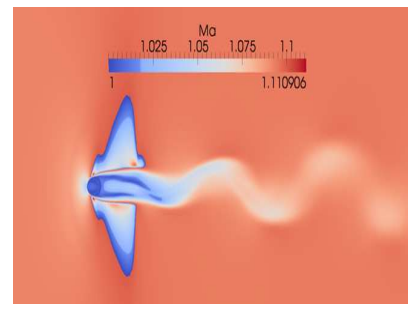

Fig. 3b Mach isocontours for a 3D unsteady flow around a sphere , $\mathrm{Ma}=0.95$ $\mathrm{Re}=600$

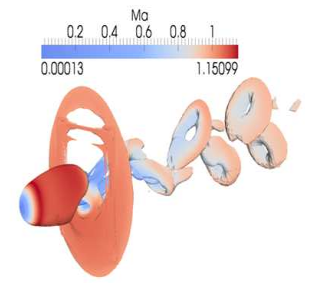

Fig. 3d Q-Criterion for a 3D unsteady flow around a sphere, $\mathrm{Ma}=0.95 \mathrm{Re}=600$

At last, the supersonic flow configurations for $M a=2$ are considered. In this case compressibility effects are very strong and all the simulations produce steady flows. Again, the analysis of the main bulk flow quantities indicate that all the physical features are accurately captured, when compared with data in the literature $[4,6]$. Isocontours are shown in figures $4 \mathrm{a}$ and $4 \mathrm{~b}$. 


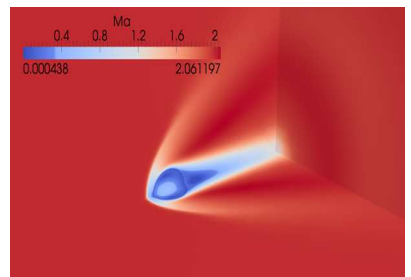

Fig. 4a Mach field of a 3D supersonic flow around a sphere, $\mathrm{Ma}=2 \mathrm{Re}=300$

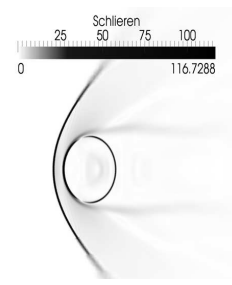

Fig. 4b Schlieren Criterion of a 3D supersonic flow around a sphere, $\mathrm{Ma}=2 \mathrm{Re}=600$

\section{Conclusion}

The flow around a sphere has been analyzed via an IBM for adiabatic compressible flows. The analysis has encompassed a wide range of $R e, M a$ for which various physical features emerge. The results of the present analysis indicate that the proposed IBM model successfully captures the physical features for the entire spectrum of configurations investigated. An accurate prediction of the main bulk quantities has been obtained and, in particular, the method has proven robustness characteristics in capturing shock features and the supersonic zone on the sphere surface.

This research work has been developed using computational resources in the framework of the project DARI-GENCI A0012A07590.

\section{References}

1. Constant, E., Favier, J., Meldi, M., Meliga, P., Serre, E. : An Immersed Boundary Method in OpenFOAM: verification and validation, Comp. Fluids, 157, 55-72 (2017).

2. Johnson, T. A. Patel, V. C. : Flow past a sphere up to a Reynolds number of 300, J. Fluid Mech., (1999).

3. Gutirrez Marcantoni, L.F., Tamagno, J.P., Elaskar, S.A. : High speed flow simulation using OpenFOAM, Mecánica Computacional, 2939-2959 (2012).

4. Krumins, V. : A review of sphere drag coefficients applicable to atmospheric density sensing, Naval Ordance Laboratory, (1972).

5. Mohd-Yosuf J. : Combined immersed boundary/B-spline methods for simulation of flow in complex geometries, Annual Research Briefs, , 317-328 (1997).

6. Nagata, T., Nonomura, T., Takahashi, S., Mizuno, Y., Fukuda, K. : Investigation on subsonic to supersonic flow around a sphere at low Reynolds number of between 50 and 300 by direct numerical simulation, Phys. Fluids, 28, 056101 (2016).

7. Peskin, CS. : Flow Patterns Around Heart Valves: A Numerical Method, J. Comp. Phys., 10, 252-271 (1972).

8. Pinelli, A., Naqavi, I.Z., Piomelli, U., Favier, J. : Immersed-boundary methods for general finite-difference and finite-volume Navier-Stokes solvers, J. Comp. Phys., 229, 9073-9091 (2010).

9. Uhlmann, M. : An immersed boundary method with direct forcing for the simulation of particulate flows, J. Comp. Phys., 209, 448-476 (2005).

10. Kurganov, A., Tadmor, E. : New high-resolution central schemes for nonlinear conservation laws and convection-diffusion equations, J. Comp. Phys., 160, 241-282 (2000). 